\title{
Transmission Electron Microscope
}

National Cancer Institute

\section{Source}

National Cancer Institute. Transmission Electron Microscope. NCI Thesaurus. Code C78813.

An electron microscope that transmits a beam of electrons through a finely sliced section of a specimen and creates an image of the sample based on its effect on the phase of the electrons that pass through. 